\title{
PEMODELAN PROSES BISNIS PENGADAAN BARANG (STOK) MENGGUNAKAN PENDEKATAN BUSINESS PROCESS MODELLING NOTATION (BPMN) (Studi Kasus: SHM Motor Purwokerto)
}

\author{
Candra Novian ${ }^{1)}$,Yusyida Munsa Idah ${ }^{2)}$, Zanuar Rifai ${ }^{3)}$ \\ 1), 2), 3) Sistem Informasi Universitas Amikom Purwokerto \\ email : sayacandran@gmail.com ${ }^{l)}$,yusyida_mi@amikompurwokerto.ac.id ${ }^{2)}$, \\ zanuar.rifai@amikompurwokerto.ac.id ${ }^{3)}$
}

\begin{abstract}
Abstraksi
Dalam organisasi tentunya sudah pasti memiliki proses bisnis yang menopang kegiatan atau aktivitas bisnis didalamnya guna mecapai visi dan misi yang teridentifikasi. Saat ini proses bisnis yang berjalan di Sahabat Hutama Mandiri atau SHM Purwokerto sudah dibantu dengan sistem inventory akan tetapi sistem tersebut masih memiliki banyak kekurangan seperti kurangnya fitur-fitur sehingga admin harus membuat pencatatan secara manual untuk bagian yang belum memiliki fitur. Maka dari itu perlu dibuat Business Process Model and Notation (BPMN) yang bertujuan untuk mengetahui proses bisnis yang terjadi di SHM Purwokerto dan, meminimalisir kesalahan yang sering terjadi pada sistem yang ada di Sahabat Hutama Mandiri Purwokerto. Hasil dari penelitian ini adalah perlu ada nya penambahan beberapa fitur-fitur seperti fitur return atau pengembalian barang yang rusak, sistem penentuan harga yang ada di sistem inventori pada Sahabat Hutama Mandiri.
\end{abstract}

Kata Kunci :

Proses Bisnis, Pemodelan, BPMN

\begin{abstract}
In the organization, of course, it certainly has business processes that support business activities or activities in it in order to achieve the identified vision and mission. Currently, the business processes running at Sahabat Hutama Mandiri or SHM Purwokerto have been assisted by an inventory system, but the system still has many shortcomings, such as the lack of features, so the admin has to make notes manually for parts that do not have features. Therefore, it is necessary to create a Business Process Model and Notation (BPMN) which aims to find out the business processes that occur at SHM Purwokerto and minimize errors that often occur in the system at Sahabat Hutama Mandiri Purwokerto. The results of this study are the need for the addition of several features such as the return feature or the return of damaged goods, the pricing system in the inventory system at Sahabat Hutama Mandiri.
\end{abstract}

\section{Keywords :}

Business Process, Modelling, BPMN

\section{Pendahuluan}

Segala aktivitas yang dilakukan perusahaan sehubungan dengan penyediaan layanan atau produk kepada pelanggannya disebut juga dengan istilah proses bisnis. Suatu organisasi tentunya memiliki proses bisnis yang mendukung kegiatan bisnis di dalam organisasi tersebut untuk mencapai visi dan misi yang telah ditetapkan. Metode penyampaian/eksekusi proses memiliki pengaruh yang besar terhadap "kualitas layanan" yang dirasakan pelanggan dalam hal efisiensi layanan yang diberikan [1]. PT. Sahabat Hutama Mandiri (SHM) Purwokerto merupakan salah satu perusahaan yang bergerak di bidang distributor Oli, knalpot motor, ban motor, dan suku cadang kendaraan bermotor. Berlokasi di Jalan A Jaelani No.22, Dusun II, Tambak sari Kidul, Kec. Kembaran, Kabupaten Banyumas, Jawa Tengah 53123.
Berdasarkan wawancara yang peneliti lakukan dengan narasumber yaitu admin gudang, untuk kondisi saat ini di SHM Purwokerto sendiri sebenarnya sudah menggunakan sistem inventori akan tetapi dalam sistemnya masih sering melakukan kesalahan. Sistem di SHM masih memiliki banyak kekurangan terutama dalam hal fitur-fitur yang ada didalamnya seperti fitur persediaan barang atau stok dimana fitur ini masih sering memberi informasi data yang salah terutama dalam hal data stok dan pada fitur ini seharusnya apabila stok barang dalam kondisi akan habis atau tinggal sedikit maka akan memberikan notifikasi berupa pemberitahuan bahwa stok barang habis, fitur pengembalian barang rusak atau return.

Fitur ini tidak ada di system padahal dengan adanya fitur ini dapat meminimalisir data stok barang rusak di perusahaan, dan masih banyak lagi. Hal ini membuat admin gudang sering melakukan kesalahan 
pada saat membuat laporan. Kesalahan sering terjadi ketika admin akan memasukan data stok gudang ke system. Lalu ada juga beberapa fitur yang belum tersedia di system sehingga membuat admin harus membuat pencatatan secara manual.

Pada penelitian ini akan dibuat suatu Business Process Model and Notation (BPMN) yang berdasarkan proses bisnis yang ada di gudang SHM agar dapat menganalisis kebutuhan system yang ada di SHM Purwokerto. Tujuannya adalah untuk mengidentifikasi dan merancang pemodelan proses bisnis menggunakan pendekatan BPMN untuk merancang proses bisnis bagian inventory Purwokerto.

\section{Tinjauan Pustaka ERP}

Enterprise resource planning (ERP) merupakan salah satu cara dalam melakukan perencanaan, pengelolaan semua hal yang terkait di dalam sebuah perusahaan [2]. ERP memiliki kemampuan dalam meningkatkan efisiensi serta meningkatkan keuntungan bagi perusahaan. Selain itu juga ERP dapat mengintegrasikan komponen-komponen bisnis yang ada di dalam sebuah perusahaan dari ulu sampai ke hilir, fleksibel, dan kemapuan menghasilkan data untuk analisis untuk perencanaan. Enterprise resource planning adalah sistem yang pada dasarnya seperangkat aplikasi bisnis yang terintegrasi bersama untuk membantu perusahaan, dalam mengumpulkan, memanajemen, dan melaporkan informasi dalam keseharian bisnis proses [3]. Aplikasi bisnis ini biasa disebut modules, dan bisa dipasang, konfigurasi bedasarkan kebutuhan proses bisnis. Dikarenakan kebutuhan dalam bisnis yang terus berubah dan meningkat, modules baru dapat ditambahkan ke dalam sistem ERP yang ada agar dapat menjawab kebutuhan bisnis baru.

\section{Business Process Modelling (BPM)}

Business Process Modelling (BPM) atau Pemodelan Proses Bisnis (PPB) merupakan diagram yang umum mewakili urutan kegiatan secara implisit berfokus pada sebuah proses, tindakan dan kegiatan (job). Sumber Daya (Resource) yang digambarkan dalam PPB menunjukkan bagaimana mereka akan diproses. Pemodelan Proses Bisnis adalah lintas fungsional, biasanya penggabungan pekerjaan dan dokumentasi lebih dari satu departemen dalam sebuah institusi, organisasi atau perusahaan. Dalam situasi lebih rumit, pemodelan Proses juga dimasukan pada aktivitas proses eksternal pada organisasi dan sistem yang dimasukkan ke dalam sebuah proses primer/utama.

Dalam organisasi besar Pemodelan Proses Bisnis cenderung dianalisis dan direpresentasikan secara lebih rinci dari pada di organisasi kecil, karena skala dan kompleksitasnya lebih besar. Manfaat Pemodelan Proses Bisnis adalah untuk memudahkan pemahaman alur proses secara terintegrasi, tujuan pemodelan proses bisnis adalah untuk mendefiniskan langkah langkah yang harus diambil untuk mencapai suatu tujuan Diagram Model Proses Bisnis adalah alat untuk mencapai sebuauh tujuan, dan bukan hasil kinerja dari suatu proses. Hasil akhir diagram proses bisnis ini adalah melakukan perbaikan pada cara proses bisnis itu bekerja. Proses bisnis itu sendiri adalah serangkaian aktivitas yang dilakukan oleh suatu bisnis dimana mencakup inisiasi input, transformasi dari suatu informasi, dan menghasilkan output [4].

\section{Value Chain Analysis}

Value chain analysis adalah proses mengidentifikasi aktivitas perusahaan dari aktivitas utama dan aktivitas pendukung [5]. Value chain analysis menganalisis aktivitas internal perusahaan dan meningkatkan nilai produk atau layanan yang diberikan. Oleh karena itu, analisis rantai nilai dapat memberikan proposisi nilai yang baik yang dapat dijalankan oleh perusahaan.

Analisis Value Chain terdiri dari dua aktivitas dengan sembilan dimensi. Pertama, lima dimensi primary activity (aktivitas utama) yakni mereka yang terlibat dalam pembuatan produk secara fisik yang terdiri dari aktivitas: inbound logistic, operations, outbound logistics, marketing atau sales dan service. Kedua, empat dimensi support activity (aktivitas pendukung), yang terdiri dari aktivitas: procurement, technological development, human resources management dan firm infrastructure atau general admistration. Sembilan dimensi value chain ini dapat digunakan untuk mengukur dan mengetahui kondisi internal industri manufaktur [6].

\section{Business Process Modelling Notation (BPMN)}

Business Process Modeling Notation (BPMN) merupakan penggambaran dari suatu bisnis proses diagram berdasarkan teknik diagram alur, dirangkai untuk membuat model-model grafis dari operasioperasi bisnis dimana terdapat aktivitas-aktivitas dan kontrol-kontrol alur yang mendefinisikan urutan kerja. BPMN dikembangkan oleh konsorsium industry yaitu konstituen yang mewakili berbagai vendor alat BPM tetapi bukan sebagai pembuka akhir, mengemukakan bahwa " The Business Process Modeling Notation is Emerging as a standard language for capturing business processes, especially at the level of domain analysis and high level systems design" [7], Diagram BPMN terdiri atas elemen. Elemen ini terbagi atas empat kategori, yaitu Flow Object, Connecting Object, Swimlanes, dan Artifact. Berikut ini merupakan penjelasan dari masing-masing elemen BPMN.
a. Flow Object
1) Event direpresentasikan dalam bentuk lingkaran dan menjelaskan apa yang terjadi saat itu. Ada dua 
jenis event, yaitu start, intermediate, dan end. Eventevent ini mempengaruhi alur proses alur proses dan biasanya menyebabkan terjadinya kejadian (trigger) atau sebuah dampak (result) Masing-masing mewakili kejadian dimulainya proses bisnis, interupsi proses bisnis, dan akhir dari proses bisnis. Untuk setiap jenis event tersebut sendiri terbagi atas beberapa jenis, misalnya message start, yang dilambangkan seperti start event namun mendapatkan tambahan lambang amplop di dalamnya, yang berarti ada pesan event tersebut dimulai dengan masuknya pesan.

2) Activity merepresentasikan pekerjaan (task) yang harus diselesaikan. Ada empat macam activity, yaitu task, looping task, sub process, dan looping subprocess.

\section{b. Connecting Object}

Connecting object merupakan aliran pesan antar proses dimana satu kejadian dengan kejadian yang lain saling berhubungan dan merepresentasikan dari hubungan tersebut. Adapun simbol-simbol atau gambar dalam penulisan connecting object ada 3 jenis yaitu :

1) Sequence flow, merepresentasikan pilihan default untuk menjalankan proses

2) Message flow, merepresentasikan aliran pesan antar proses

3) Association, digunakan untuk menghubungkan elemen dengan artifact

\section{c. Swimlanes}

Elemen ini digunakan untuk mengkategorikan secara visual seluruh elemen dalam diagram. Ada dua jenis swimlanes, yaitu pool dan lane. Perbedaannya adalah lane terletak di bagian dalam pool untuk mengkategorisasi elemen-elemen di dalam pool menjadi lebih spesifik.

\section{d. Artifacts}

Elemen ini digunakan untuk memberi penjelasan di diagram. Elemen ini terdiri atas tiga jenis, yaitu:

1) Data object, digunakan untuk menjelaskan data apa yang dibutuhkan dalam proses

2) Group, untuk mengelompokkan sejumlah aktivitas di dalam proses tanpa mempengaruhi proses yang sedang berjalan

3) Annotation, digunakan untuk memberi catatan agar diagram menjadi lebih mudah dimengerti. Notasi BPMN diatas dapat memodelkan pesan kompleks yang dilewatkan diantara pelaku bisnis atau bagian dari pelaku bisnis, Salah satu kelebihan diagram BPMN adalah kemampuan dalam memodelkan aliran pesan karena dapat menggambarkan secara grafis pemisahan aliran proses berdasarkan organisasi atau departemen yang melakukannya.
Analisis Gap adalah salah satu alat yang dapat digunakan untuk mengevaluasi kinerja karyawan. Gap analisys atau analis kesenjangan juga ialah salah satu langkah yang sangat penting dalam tahapan perencanaan ataupun tahap evaluasi kerja. Metode ini ialah salah satu metode yang sangat umum digunakan dalam pengelolaan manajemen internal suatu lembaga [8]. Secara harfiah "gap" mengidentifikasikan adanya suatu perbedaan (disparity) antara satu hal dengan hal yang lain. Gap analysis sering digunakan di bidang manajemen serta menjadi salah satu alat yang digunakan untuk mengukur kualitas pelayanan (quality of service). Bahkan pendekatan ini sangat sering digunakan di Amerika Serikat untuk memonitor kualitas pelayanan. Dalam bisnis analisa gap digunakan untuk menentukan langkah- langkah apa yang perlu diambil untuk berpindah dari kondisi saat ini ke kondisi yang diinginkan atau keadaan masa depan yang diinginkan. Analisa gap terdiri dari tiga komponen faktor utama yaitu:

a. Daftar karakteristik (seperti atribut, kompetensi, tingkat kinerja) dari situasi sekarang (apa yang saat ini).

b. Daftar apa yang diperlukan untuk mencapai tujuan masa depan (apa yang harus).

c. Daftar kesenjangan apa yang ada dan perlu diisi.

\section{Odoo}

Odoo merupakan aplikasi web yang dibangun dengan menggunakan bahasa pemrograman Python, XML, Javascript, dan Postgresql sebagai databasenya [9]. Secara historis, Odoo pertama kali disebut TinyERP, kemudian diubah namanya menjadi OpenERP pada tahun 2009, kemudian dikembangkan lebih lanjut di versi 8 dan berganti nama menjadi Odoo. Odoo juga merupakan salah satu aplikasi aplikasi enterprise resource planning (ERP) yang ditulis dalam format open source. Odoo adalah satu-satunya sistem manajemen yang digunakan oleh perusahaan kecil dan menengah dan perusahaan independen serta perusahaan besar. Odoo juga bisa diterapkan di berbagai zona seperti zona perdagangan, tekstil dan pertanian. Perbedaan ini menunjukkan fleksibilitas besar Odoo untuk mengakses semua jenis perusahaan yang ada.

Berikut kelebihan- kelebihan yang dimiliki oleh Odoo:

a. Akses informasi yang dapat dipercaya.

b. Menghindari redundansi dari pemasukan data dan operasi.

c. Mengurangi waktu jeda waktu penampilan informasi dan laporan.

d. Pengurangan biaya, penghematan waktu, dan peningkatan control dengan analisis skala enterprise.
e. Modul
CRM
(Customer
Relationship 


\section{Metode Penelitian}

Teknik pengumpulan data ini dilakukan agar datadata yang dibutuhkan dalam penelitian ini dapat terpenuhi dan agar tercapainya tujuan penelitian. Berikut merupakan teknik pengumpulan data yang dilakukan pada penelitian ini.

\section{Study Literatur}

Teknik ini dilakukan dengan tujuan untuk mengungkapkan berbagai teori- teori yang relevan dengan permasalahan yang tengah dihadapi atau diteliti sebagai bahan referensi dalam ulasan hasil penelitian yang akan diteliti. Studi literatur yang dilakukan didalam penelitian ini yaitu dengan mencari beberapa buku, jurnal, dan situs web yang berkaitan dengan tugas akhir skripsi yang ada di internet untuk mencari landasan teori serta penelitian yang terkait dengan permasalahan yang ditemukan.

\section{Observasi}

Pada kegiatan observasi dimulai dengan melakukan pengamatan langsung terhadap proses bisnis dan strategi bisnis di organisasi,

mengamati apa saja yang menjadi dukungan agar proses bisnis dapat berjalan sesuai dengan yang diinginkan oleh instansi, melihat sejauh mana pemanfaatan sistem dan teknologi informasi di organisasi tersebut, serta mencari data dan informasi terkait lainnya yang diperlukan untuk penelitian. Teknik observasi dilakukan untuk mempelajari dan memperoleh gambaran nyata dari setiap aktivitas bisnis, serta dukungan apa saja yang sudah ada agar aktivitas- aktivitas bisnis tersebut dapat berjalan sesuai dengan tujuan organisas. Dalam penelitian ini metode observasi lebih kepada mengamati mengenai proses bisnis yang ada di SHM Purwokerto. Selain proses bisnis adapun peneliti mengamati situasi dan kondisi perusahaan SHM Purwokerto.

\section{Wawancara}

Dalam penelitian ini peneliti melakukan wawancara dengan narasumber adalah Bapak Gano selaku karyawan dan juga sebagai admin gudang di bagian pengadaan stok barang di gudang (inventory). Beliau yang memegang dan bertanggung jawab atas proses bisnis pengadaan barang (inventory) yang berjalan di PT SHM. Dalam proses wawancara peneliti sudah menyiapkan beberapa pertanyaan yang lengkap dan rinci terkait proses bisnis yang ada di SHM Purwokerto. Metode ini digunakan untuk mendapatkan data tentang proses bisnis yang terjadi di SHM Purwokerto.

\section{Dokumen}

Dalam hal ini, teknik dokumentasi diartikan sebagai metode pengumpulan informasi dengan mencatat atau mengutip informasi yang sudah terdapat dalam dokumen atau arsip [10].

Dokumen adalah catatan tertulis tentang berbagai kegiatan atau peristiwa pada waktu yang lalu.
Metode ini digunakan untuk memperoleh data tentang proses bisnis (kegiatan bisnis), kondisi gudang SHM Purwokerto, dan faktur-faktur pembelian barang. Bagian ini memuat penjelasan secara lengkap dan terinci tentang langkah-langkah yang dilakukan dalam melakukan penelitian ini. Selain itu, langkah penelitian juga perlu ditunjukkan dalam bentuk diagram alir langkah penelitian atau framework secara lengkap dan terinci termasuk di dalamnya tercermin algoritma, rule, pemodelanpemodelan, desain dan lain-lain yang terkait dengan aspek perancangan sistem.

\section{Konsep Penelitian}

Langka-langkah atau alur kegiatan penelitian yang dilakukan di SHM motor. Di jelaskan sebagai berikut:

a. Pengumpulan Data

Dalam hal ini peneliti akan mencari data dengan cara wawancara, observasi, dan dokumen.

\section{b. Value Chain Analysis}

Value chain analysis menganalisis aktivitas internal perusahaan yang berkaitan dengan pengadaan barang (inventory), pembelian (stock), dan penjualan (sales).

\section{c. Business Process Modeling Notation (BPMN)}

Seluruh informasi yang telah dikumpulkan, peneliti akan dibuat pemodelan BPMN sesuai dengan informasi yang telah diberikankan oleh pihak Sahabat Hutama Mandiri (SHM).

\section{d. Analisis GAP dengan Fitur Odoo}

Pada proses ini setelah mengetahui BPMN dan activity, maka peneliti akan melakukan analisis pada seluruh bisnis proses dimana seluruh bisnis proses, aktivitas dan informasi sudah terakomodir dalam fitur Odoo yang akan digunakan atau belum.

\section{Hasil dan Pembahasan \\ Pengumpulan Data}

Metode pengumpulan data yang dilakukan didalam penelitian ini yaitu dengan metode observasi dan wawancara secara langsung. Metode observasi yang dilakukan adalah dengan peneliti melakukan pengamatan secara langsung mengenai jalannya proses bisnis yang ada di Sahabat Hutama Mandiri (SHM) Purwokerto tempat peneliti melaksanakan penelitian dan mencatat semua informasi yang mendukung dalam penyusunan laporan penelitian. Sementara untuk metode wawancara peneliti mengajukan pertanyaan- pertanyaan secara bebas baik terstruktur maupun tidak terstruktur mengenai data dan informasi mengenai Sahabat Hutama Mandiri Purwokerto.Data yang didapat peneliti merupakan data kualitatif atau data yang tidak dapat dihitung. 


\section{Value Chain Analysis}

Dibawah ini merupakan aktivitas utama dan juga aktivitas pendukung yang terjadi di Sahabat Hutama Mandiri (SHM) Purwokerto yang digambarkan dengan value chain sebagai berikut :

1. Aktivitas Utama dalam kegiatan Bisnis di SHM a. Inbound Logistics

Pada bagian Inbound Logistics aktivitas yang terjadi adalah SHM melakukan kegiatan memesan barang kepada supplier. Supplier mengirim produk yang di pesan ke SHM dan SHM pun menerima barang dari supplier.

\section{b. Operation}

Aktivitas pada bagian operation produk disimpan di gudang lalu di sortir oleh staf gudang. staf gudang melakukan pengecekan stok barang yang ada di gudang.

c. Outbound Logistics

Pada aktivitasi ini, aktivitas yang terjadi adalah gudang menerima pesanan dari customer lalu menyiapkan pesanan dan mengecek produk yang akan dikirim ke customer. Sales melakukan pengiriman pesanan ke customer.

\section{d. Marketing and Sales}

Pada aktivitas marketing and sales, salesman akan melakukan penjualan dengan cara door to door yaitu dimana salesman mendatangi customer dan melakukan penawaran produk yang dijual, setelah itu salesman akan meminta data customer. Selain itu salesman juga akan membagikan dan menyebarkan brosur ke setiap tempat yang dikunjungi. Salesman akan memberikan bonus berupa kaos, kalender, dan juga diskon bagi customer yang sering membeli produk.

\section{e. Service}

Untuk aktivitas service adalah adanya fasilitas antar produk atau barang ke tempat customer yaitu pesanan di antar oleh sales dari SHM ke tempat customer dengan syarat minimal pembelian produk. Lalu ada juga layanan pengembalian produk, penukaran produk, dan garansi untuk setiap produk yang dibeli.

\section{Aktivitas pendukung dalam kegiatan Bisnis di SHM}

a. Firm Infrastructure

Firm infrastructure terdiri dari manajemen umum dan juga struktur organisasi yang ada di SHM Purwokerto.

b. Human Resource Management

Pada aktivitas ini pada SHM perlu melakukan perekrut karyawan baru dan pelatihan kepada karyawan baru.

c. Technology Development
Pada aktivitas ini SHM melakukan pengembangan terhadapresearch and development, serta menerapkan system ERP.

\section{d. Procurement}

Aktivitas ini perusahaan perlu melakukan pembelian barang investaris seperti mesin-mesin, kendaraan operasional. Selain itu pencarian supplier yang akan membantu dalam proses bisnis.

\section{Business Process Model and Notation (BPMN)}

Dibawah ini merupakan gambar dari BPMN dari proses bisnis yang ada di Sahabat Hutama Mandiri (SHM). Informasi ini didapatkan bersumber pada hasil wawancara serta observasi secara langsung kepada objek riset. Berikut ini merupakan penjelasan dari Business Process Model and Notation (BPMN) dari proses bisnis yang ada di Sahabat Hutama Mandiri (SHM).

\section{Proses Pengecekan stok di Gudang}

Alur dari proses pengecekan stok di gudang di SHM yang sedang berjalan, antara lain :

a. Admin melakukan pengecekan data barang yang ada di gudang (persediaan barang baik barang masuk maupun keluar).

b. Admin melakukan pencatatan barang yang ada di gudang.

c. Admin masuk ke system dengan cara login memasukan username dan password.

d. Admin memasukan data persediaan barang ke system.

\section{Proses Pemesanan Barang ke Supplier Berjalan}

Alur proses pemesanan yang sedang berjalan di SHM antara lain :

a. Staf gudang membuat permintaan pembelian stok dan memberikannya ke admin gudang.

b. Admin gudang menerima permintaan pembelian stok dan melakukan pemesanan order ke supplier.

c. Supplier menerima pesanan dan membuat surat jalan lalu mengirim barang pesanan ke gudang SHM. d. Admin gudang menerima barang pesanan dan mengecek kesesuaian barang pesanan apabila sesuai maka admin menerima faktur pembelian dan melakukan pembayaran, namun barang yang tidak sesuai akan segera di konfirmasi ke supplier untuk dikembalikan

e. Setelah melakukan pembayaran admin gudang menyerahkan barang ke staf gudang untuk disimpan.

\section{Proses Penyimpanan Barang di Gudang}

Alur proses penyimpanan barang digudang yang berjalan antara lain :

a. Admin menerima barang dari supplier dan menyerahannya ke staf gudang.

b. Staf gudang menerima dan memisahkan barang yang berkualitas bagus dan yang rusak.

c. Staf mengupdate stok barang yang ada di gudang dan menyimpan barang di gudang. 


\section{Proses Update Barang}

Alur proses penyimpanan barang digudang yang berjalan antara lain :

a. Staff membuat data di system untuk produk baru.

b. Staff memasukan kode barang dan nama barang ke system.

c. Staff memasukan harga barang.

\section{Proses Sales Canvas Meminta Data Stok Berjalan}

Alur proses sales canvas meminta data stok barang ke gudang yang berjalan antara lain :

a. Sales canvas meminta data barang yang ada di gudang ke admin.

b. Admin menerima permintaan dan mencetak data stok persediaan di gudang.

c. Admin mengecek kembali data barang dan memberikannya ke sales canvas.

d. Sales canvas menerima cetak data yang berisi data barang.

\section{Proses Pengecekan stok di Gudang}

Usulan Alur proses pengecekan stok di gudang usulan antara lain :

a. Admin masuk ke system inventory dengan memasukan password dan username. Dan system memberi notifiksi beberapa barang yang habis atau hampir habis

b. Admin melakukan mencetak data barang yang habis.

\section{Proses Pemesanan Stok Barang ke Supplier}

Usulan Alur proses pemesanan stok barang ke supplier usulan antara lain :

a. Staf gudang cek stok barang yang ada di database dan melakukan pemesanan via telepon.

b. Supplier menerima pemesanan, membuat surat jalan, dan mengirimkan barang pesanan ke gudang.

c. Staf gudang menerima barang pesanan, melakukan pengecekan barang apabila ada yang tidak sesuai atau rusak maka akan segera mengkonfirmasi ke supplier sementara barang yang sudah sesuai akan masuk gudang.

d. Staf gudang menerima bukti pembayaran dan melakukan pembayaran sesuai dengan nota dari supplier.

e. Staf gudang melakukan input data barang dan mencetak laporan syok barang untuk dilakukan pengecekan barang.

f. Laporan diberikan kepada admin gudang untuk dilakukan pengecekan barang.

g. Admin menyusun stok barang.

\section{Proses Sales Canvas Meminta Data Stok Usulan}

Alur proses sales canvas meminta data stok ke gudang usulan antara lain :

a. Sales canvas mengecek data stok digudang dengan mengakses system melalui handphone. b. Sales canvas mengecek jumlah data stok di gudang.

\section{Analisis GAP}

Analisis GAP yang dibuat di Sahabat Hutama Mandiri berdasarkan BPMN dengan menggunakan aplikasi dan fitur yang ada di Odoo. Dibawah ini merupakan tabel analisis GAP yang ada di Sahabat Hutama Mandiri (SHM) Purwokerto.

Tabel 1. Analisis GAP

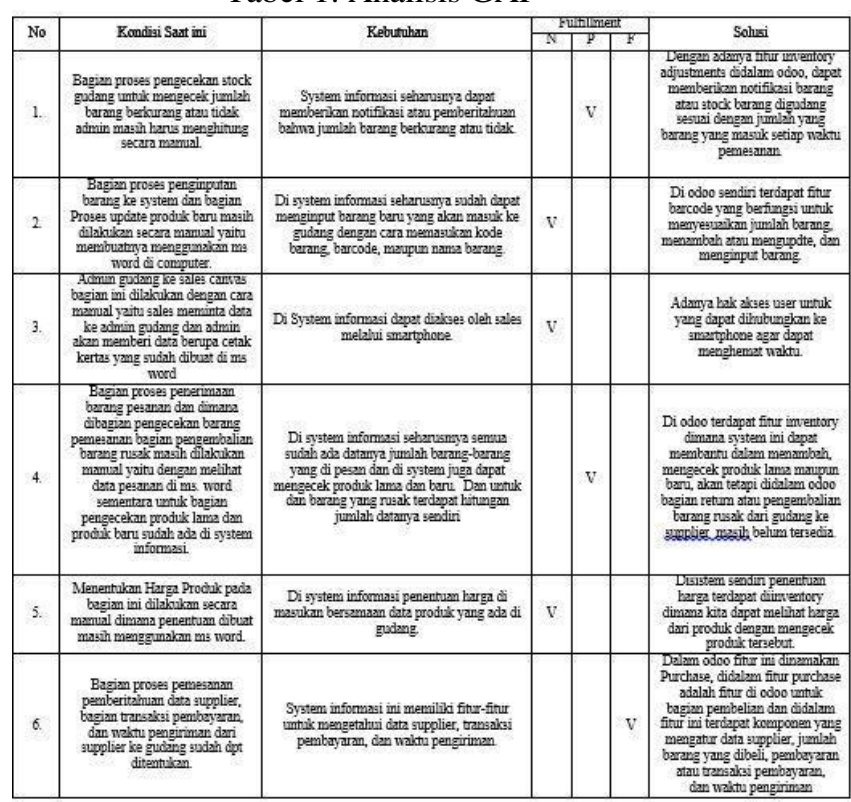

Keterangan:

$\mathrm{N}$ (Non) : Kondisi saat ini tidak memenuhi kebutuhan yang disesuaikan dengan Odoo

P (Performing) : Kondisi saat ini sebagian memenuhi kebutuhan yang disesuaikan dengan Odoo

F (Financing) : Kondisi saat ini sudah memenuhi kebutuhan yang disesuaikan dengan Odoo

\section{Kesimpulan dan Saran}

\section{Kesimpulan}

Berdasarkan hasil penelitian pemodelan proses bisnis pengadaan barang (stok) menggunakan pendekatan business process modelling notation (BPMN) yang telah dilakukan, maka dapat diambil kesimpulan sebagai berikut :

1. Sistem inventori Belum bisa digunakan dengan maksimal karena ada beberapa fitur yang belum terintegrasi dengan baik, sehingga perlu adanya penambahan-penambahan beberapa fitur pendukung seperti fitur return atau pengembalian barang pesanan, penentuan harga barang, dan lain-lain serta perbaikan pada system inventory yang berjalan.

2. Sistem inventori baru dapat diakses di komputer, hal ini membuat hak akses terbatas sehingga perlu adanya penambahan hak akses untuk masuk ke sistem agar dapat lebih mudah dalam menjalankan kegiatan atau aktivitas bisnis.

\section{Saran}


1. Untuk Penelitian selanjutnya dapat menambahkan pada tahapan analisis risiko, tahapan UML, dan Usecase, serta Activity Diagram dan Sequence Diagram didalam melakukan pemodelan proses bisnis.

2. Cakupan penelitian dapat diperluas untuk fokusnya tidak hanya bagian inventory saja tetapi juga bagian lain seperti penjualan, marketing, dll.

\section{Daftar Pustaka}

[1] M. Dumas, M. La Rosa, J. Mendling, and H. A. Reijers, Fundamentals of Business Process Management. 2013.

[2] F. Purwaningtias and C. Mukmin, "Pemodelan Enterprise Resource Planning Menggunakan Odoo Pada Z-Tech Komputer," Klik - Kumpul. J. Ilmu Komput., vol. 6, no. 3, p. 275, 2019, doi: 10.20527/klik.v6i3.259.

[3] R. Wijaya, A. Wibowo, and R. Adipranata, "Aplikasi Enterprise Resource Planning Bagian Modul Penjualan di Lima Perusahaan Distributor dan Dealer," J. Infra, vol. 4, no. 2, pp. 3-9, 2016.

[4] P. Harmon, Business Process Change: A Manager's Guide to Improving, Redesigning, and Automating Processes. San Francisco: Morgan Kaufmann Pubishers, 2003.

[5] A. Sovia Pramudita, "Formulasi Model Bisnis Hostel di Bandung dengan Pendekatan Value Chain dan Business Model Canvas (Studi Kasus: Pinisi Backpacker)," ISEI Bus. Manag. Rev., vol. II, no. 1, pp. 32-38, 2018, [Online]. Available:

http://jurnal.iseibandung.or.id/index.php/ibmr.

[6] Hendri, "ANALISIS VALUE CHAIN DI INDUSTRI OTOMOTIF," J. PASTI, vol. XI, no. 1, pp. 55-64, 2016.

[7] K. S. Mirza, "Rancang bangun aplikasi rekrutmen dan seleksi pegawai berdasarkan kompetensi pada RSIA Putri Surabaya," Institut Bisnis dan Informatika STIKOM Surabaya, 2018.

[8] Y. Muchsam, Falahah, and G. I. Saputro, "Penerapan Gap Analysis Pada Pengembangan Sistem Pendukung," Semin. Nsional Apl. Teknol. Inf., vol. 2011, no. Juni 2011, p. A-94A-100, 2011.

[9] C. A. Lestari and Suhendi, "Implementasi Odoo Dengan Modul Accounting and Finance Di SD Islam Tunas Mandiri," J. Inform. Terpadu, vol. 3, no. 1, pp. 1-6, 2017.

[10]Djaali, Metodologi Penelitian Kuantitatif. Jakarta: Bumi AKsara, 2021. 